\title{
Maternal hormone levels among populations at high and low risk of testicular germ cell cancer
}

\author{
Y Zhang', BI Graubard', MA Klebanoff', C Ronckers', FZ Stanczyk ${ }^{3}$, MP Longnecker ${ }^{4}$ and KA McGlynn*, \\ 'Division of Cancer Epidemiology and Genetics, National Cancer Institute, NIH, DHHS, 6120 Executive Blvd., EPS-7060, Rockville, MD 20852, USA; \\ ${ }^{2}$ National Institute of Child Health and Human Development, NIH, DHHS, Rockville, MD, USA; ${ }^{3}$ Reproductive Endocrine Research Laboratory, University \\ of Southern California Keck School of Medicine, Los Angeles, CA, USA; ${ }^{4}$ National Institute of Environmental Health Sciences, NIH, DHHS, Research \\ Triangle Park, NC, USA
}

Ethnic differences in maternal oestrogen levels have been suggested as explaining the significantly higher risk of testicular germ cell tumours (TGCT) of white men than black men in the United States. We therefore examined levels of maternal oestrogens, as well as testosterone and alphafetoprotein (AFP), in I 50 black and I 50 white mothers in the Collaborative Perinatal Project. Serum levels of estradiol (total, free and bioavailable), estriol, testosterone (total, free and bioavailable), sex hormone binding globulin (SHBG), and AFP were examined during first and third trimesters. We found that the black mothers, rather than the white mothers, had significantly higher estradiol levels in first trimester $(P=0.05)$. Black mothers also had significantly higher levels of all testosterone $(P<0.00 \mathrm{I})$ and AFP $(P<0.00 \mathrm{I})$ in both trimesters. In addition, the ratios of sex hormones (estradiol/testosterone) were significantly lower among black mothers. These findings provide little support to the oestrogen hypothesis, but are consistent with higher levels of testosterones and/or AFP being associated with reduced risk of TGCT; alternatively, lower oestrogen/androgen ratios may be associated with reduced risk.

British Journal of Cancer (2005) 92, I787- 1793. doi:I0.1038/sj.bjc.6602545 www.bjcancer.com

Published online 19 April 2005

(c) 2005 Cancer Research UK

Keywords: maternal hormone levels; testicular germ cell cancer; ethnic differences; undescended testes

The incidence rate of testicular germ cell tumours (TGCT) among white men in the United States is roughly five times higher than the rate among black men. In addition, the incidence among white men has been increasing during the past several decades (Zheng et al, 1996; McGlynn et al, 2003; Ries et al, 2004), while the incidence among black men has only recently begun to rise (McGlynn et al, 2003). The reason for this pronounced ethnic difference in risk is unknown.

Both molecular and epidemiologic studies have provided evidence that malignant transformation of testicular germ-cells occurs during early development (Rorth et al, 2000). It has been suggested that carcinoma in situ of the testis, a precursor of TGCT, has its origins in fetal life (Rorth et al, 2000) and that subnormal androgen exposure and/or increased oestrogen exposure are potentially important risk factors (Skakkebaek et al, 2001). Moreover, it is hypothesised that a disturbance in the fetal programming of gonadal development resulting from an intrauterine hormonal imbalance may delay differentiation of germ cells and render them more susceptible to malignant transformation (Rajpert-De Meyts et al, 1998).

A well-known hypothesis concerning TGCT has postulated that increased oestrogenic exposure during fetal life is associated with risk (Henderson et al, 1979; Sharpe and Skakkebaek, 1993). While

*Correspondence: Dr KA McGlynn; E-mail: mcglynnk@mail.nih.gov Received 13 December 2004; revised 21 February 2005; accepted 25 February 2005; published online 19 April 2005 some studies have supported this hypothesis (Moller and Skakkebaek, 1997; Sabroe and Olsen, 1998), two direct examinations of maternal hormone levels have not (Henderson et al, 1988; Troisi et al, 2003a). The direct examinations may have been hampered, however, by somewhat limited sample sizes and by studying samples drawn at only one time in pregnancy.

We have compared maternal serum levels of estradiol (total, free and bioavailable), estriol, sex hormone binding globulin (SHBG), testosterone (total, free and bioavailable) and alphafetoprotein during first and third trimesters in black and white populations with contrasting risks of TGCT.

\section{METHODS}

\section{Study population}

In order to examine the hypotheses of interest, a retrospective study of 150 pairs of black and white mothers was conducted among the participants of the United States Collaborative Perinatal Project (CPP). The CPP was a cohort study originally designed to examine perinatal risk factors for neurologic disorders in offspring (Niswander and Gordon, 1972). The study enrolled 41796 pregnant women seen at 12 medical centres (Baltimore, Boston, Buffalo, Memphis, Minneapolis, New Orleans, New York (two centres), Philadelphia, Portland, Providence, and Richmond) in the United States between 1959 and 1965. Some women had more than one pregnancy during the study, resulting in approximately 
55000 births, of which 13248 were white boys and 13109 were black boys. The children born during the study were followed up until age 7 years. The mothers were asked to donate nonfasting blood samples at approximately 8-week intervals throughout their pregnancies. Serum samples have been stored in glass vials at $-20^{\circ} \mathrm{C}$ with no recorded thaws.

Based on previous reports of differences in maternal hormone levels, power calculations determined that it would be necessary to examine samples from 150 white and 150 black mothers. Mothers were selected for inclusion based on characteristics of both the mother and the baby. Inclusion criteria based on characteristics of the mother were: first pregnancy, length of gestation between 26 and 48 weeks, and availability of blood samples from both first and third trimesters. Inclusion criteria based on characteristics of the baby were: male gender, singleton birth, birthweight equal to or greater than $500 \mathrm{~g}$, baby lived for at least 1 year, and had no diagnoses of undescended testes, late descending testes, retractile testes or other malformations possibly related to maternal hormone levels (i.e., CNS and related musculoskeletal, genitourinary, inguinal hernia, hydrocele, supernumerary nipples).

A total of 162 black and 652 white mothers satisfied the study inclusion criteria. The principal limiting criterion was the availability of first trimester samples as the median entry time into the study for the whole CPP population was 20 weeks gestation. In addition, the nulliparity criterion restricted the study group to approximately one-third of the whole population. Each of the 162 black mothers was matched to a white mother on the closest blood draw dates. The matches were then reordered to select the 150 pairs best matched on draw dates.

\section{Laboratory assays}

All hormone levels were assessed at the Reproductive Endocrine Research Laboratory of the University of Southern California Keck School of Medicine. Estriol, estradiol, and testosterone were determined by well-established and validated radioimmunoassay methods that are carried out routinely in the laboratory (Katagiri et al, 1974; Goebelsmann et al, 1979). Estriol was first extracted with hexane: ethyl acetate $(10: 1)$ to remove estrone and estradiol. Estriol in the aqueous fraction was then extracted with hexane: ethyl acetate $(3: 2)$. A separate serum sample was used to extract testosterone and estradiol, using ethyl acetate: hexane $(3: 2)$. This was followed by isolation of the two steroids using Celite column partition chromatography using ethylene glycol as the stationary phase. Testosterone and estradiol were eluted with $15 \%$ ethyl acetate in isooctane and $40 \%$ ethyl acetate in isooctane, respectively. Appropriate tritiated internal standards were added to each serum sample, prior to organic solvent extraction, to follow procedural losses. After drying each fraction, the estriol fraction was reconstituted in ethanol and the other fractions in assay buffer. An aliquot of each was taken to determine procedural loss, and duplicate aliquots were taken for the RIA of each hormone. Each RIA utilises an iodinated radioligand in conjunction with a specific antiserum (Diagnostic Systems Laboratories (DSL), Webster, TX, USA). A 7-point standard was included in each assay. After an overnight incubation (16-18 h), antibody-bound steroid was separated from unbound steroid by precipitation of the first antibody with a second antibody (DSL), and subsequent centrifugation.

Sex hormone binding globulin was quantified by direct chemiluminescent immunoassay using the Immulite analyzer (Diagnostic Products Corporation, Inglewood, CA, USA). The SHBG concentration and an average albumin concentration of pregnant women were then utilised in a validated algorithm with total testosterone and total estradiol, respectively, to calculate free testosterone; free- and albumin-bound testosterone (bioavailable testosterone); free estradiol; and free- and albumin-bound estradiol (bioavailable estradiol) (Sodergard et al, 1982).
Alphafetoprotein was quantified in serum by a solid-phase, twosite sequential chemiluminescent immunometric assay on the Immulite Analyzer (Diagnostic Products Corporation, Inglewood, CA, USA). The calibration range was up to $300 \mathrm{IU} \mathrm{ml}^{-1}$, using the WHO 1st International Standard 72/225. The analytical sensitivity of the assay was $0.2 \mathrm{IU} \mathrm{ml}^{-1}$. Various dilutions of samples $(N=3)$ with high AFP levels demonstrated linearity, with observed/ expected values ranging from 97 to $114 \%$. Evaluation of assay specificity showed nondetectable crossreactivity with a variety of relevant proteins, for example, albumin, haemoglobin, transferrin, IgG.

A total of 68 samples from a single blood pool was assayed for quality control purposes. Each sample was assigned a unique, random identification number in order to blind subject identities. Samples were analysed in a total of 17 batches with each batch containing four quality control samples. The intra-assay coefficients of variation ranged between 3.7 and $12.6 \%$ for all hormones, while the inter-assay coefficients of variation ranged between 4.8 and $13.3 \%$.

\section{Statistical analysis}

Ratios of sex hormones were calculated using serum levels of total, free, and albumin-bound estradiol divided by serum levels of total, free, and albumin-bound testosterone, respectively. The ratios and serum hormone levels were logarithmically transformed to achieve approximately normal distributions and the transformed values were used in all statistical analyses. The geometric means of the hormone levels are presented. $T$-tests were employed for the mean comparison of potential confounding variables. Unmatched analysis of covariance (ANCOVA) was first used to compare mean log hormone levels and mean log hormone ratios between black and white mothers by trimester (first and third trimester), adjusting only for gestational age at blood draw. In subsequent analyses, adjustment was also made for maternal age, socioeconomic index, body weight (prepregnancy weight for first trimester and weight at delivery for third trimester) as continuous variables, and smoking status at registration as a categorical variable. Maternal age and socioeconomic index were included because they differed significantly between the white and black mothers. Although maternal weight and smoking status at registration did not differ significantly, adjusting for them resulted in changes of varying magnitude in the mean log hormone levels. Thus, they were also included in the final models. Pair-matched ANCOVA was used to test for differences between first and third trimester for each ethnic group. The statistical models for this matched analysis included an intercept for each mother, which adjusts for mother-level covariates. The homogeneity of betweentrimester differences between the racial groups were determined using matched ANCOVA models by testing for an interaction between trimester and ethnicity after adjusting for the covariates that varied by trimester (i.e., gestational age at blood draw and body weight). Statistical analyses for this study were performed using the SAS system, version 8.02 (SAS Institute, Inc., Cary, NC, USA).

\section{RESULTS}

A comparison of demographic characteristics of the participants found that the black mothers were younger and of lower socioeconomic status than the white mothers (Table 1). No significant differences in age at menarche, maternal height, prepregnancy weight, weight at delivery, or smoking were observed.

Hormone levels were first examined after adjusting solely for gestational ages at blood draw (Table 2). There were no significant differences between the black and white mothers' levels of 
Table I Selected characteristics of white and black mothers

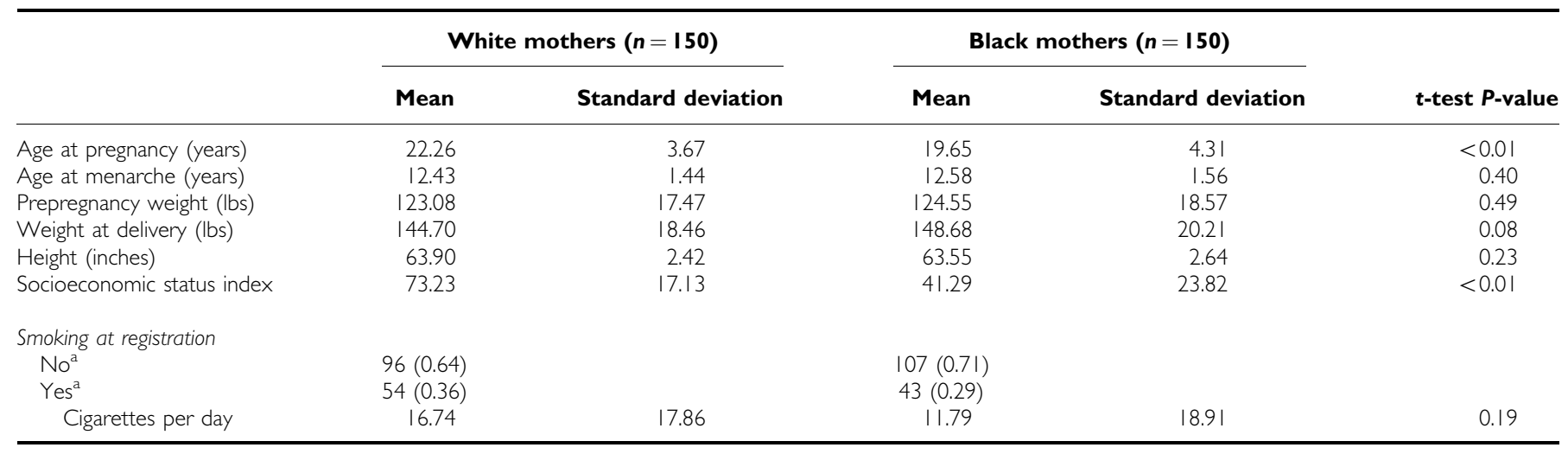

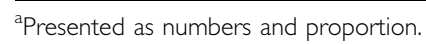

estradiols or estriol in first trimester. In third trimester, however, white mothers had significantly lower levels of SHBG, which resulted in their having significantly higher levels of free and bioavailable (free plus albumin-bound) estradiol. In addition, all testosterone levels (total, free, and bioavailable) and AFP levels were significantly higher among black mothers in both first and third trimesters. The ratios of testosterones to estradiols were also significantly different at both times, with black mothers having lower ratios than white mothers.

All hormone levels were re-examined after adjustment for maternal age, smoking status, socioeconomic status, and maternal weight, in addition to gestational ages at blood draw (Table 2). The adjustment affected both the estradiol and the SHBG findings. After adjustment, black mothers had significantly higher levels of total estradiol in first trimester $(P=0.05)$, but in third trimester, there was no difference between any of the estradiol levels, or in SHBG levels. Similar to the unadjusted results, estriol levels did not vary between the black and white mothers at either time. Also in agreement with the unadjusted results, black mothers' levels of all testosterones and of AFP remained significantly higher than white mothers' levels and black mothers' estradiol/testosterone ratios remained significantly lower than the ratios among white mothers at both time points.

Except for free and bioavailable testosterone, all other hormone levels and hormone ratios increased significantly from the first trimester to the third trimester in both white and black mothers (Table 3). The increases, however, were significantly greater among white mothers than black mothers for free estradiol, bioavailable estradiol, AFP, and for the hormone ratios. No significant difference was observed for the change in levels among the other measured hormones between white and black mothers. With the exception of AFP, all other hormones between first and third trimesters were significantly correlated in both black and white mothers (Table 4).

\section{DISCUSSION}

It has long been suggested that exposure to maternal oestrogens is associated with TGCT (Henderson et al, 1979; Sharpe and Skakkebaek, 1993). Three potential mechanisms have since been postulated: (1) suppression of androgen production, (2) suppression of androgen receptor expression, and (3) suppression of secretion of insulin-like hormone 3 (Insl3) (Sharpe, 2003). It is clear that the first two mechanisms are directly associated with reduced androgen exposure. Insl3 is responsible for the transabdominal phase of testicular descent during first trimester through virilisation and outgrowth of the embryonic gubernaculum (Nef and Parada, 1999). Exposure to maternal oestrogens, including
$17 \alpha$ - and $\beta$-estradiol, as well as diethylstilbestrol, downregulates Insl3 expression in embryonic Leydig cells (Emmen et al, 2000; Nef et al, 2000). On the other hand, based on the finding that oestrogens negatively regulate Leydig cell development via inhibition of replication of Leydig-cell precursor cells in adult and prepubertal rats, it is suggested that this regulatory mechanism may also control the number of Leydig cells in fetal life in humans (Sharpe and Skakkebaek, 1993). As Leydig cells are the source of testosterone and Insl3, if the above pathway is correct, the reduced number of Leydig cells resulting from the excess of oestrogen would decrease the production of testosterone and Insl3. Thus, elevated oestrogens during early pregnancy would, in theory, not only reduce the Insl3 expression but might also decrease testosterone production, and thus, result in an increased risk of TGCT. It should be noted, however, that the majority of undescended testes are located in the inguinal canal, rather than in the abdomen, suggesting a failure in the second, androgendependent, phase of descent rather than in the Insl3-dependent first phase. A more androgenic milieu during third trimester, then, may favour descent, in contrast with a less androgenic milieu.

Ethnic differences in maternal oestrogen and androgen levels have been reported by several epidemiologic studies. Also examining mothers in the CPP, Henderson et al (1988) studied first timester serum samples from 20 white and 20 black women and found no significant differences in levels of estradiol (total and free), SHBG or human chorionic gonadotropin. Contrary to expectation, the levels of total estradiol and free estradiol were higher in the black mothers (mean total estradiol $=189.4 \mathrm{pg} \mathrm{dl}^{-1}$; mean free estradiol $=1.66 \mathrm{pg} \mathrm{dl}^{-1}$ ) than the white mothers (mean total estradiol $=138.4 \mathrm{pg} \mathrm{dl}^{-1}$; mean free estradiol $=1.28 \mathrm{pg} \mathrm{dl}^{-1}$ ). The authors also reported that the black mothers had significantly higher levels of testosterone $\left(114.4 \mathrm{ng} \mathrm{dl}^{-1}\right)$ than did the white mothers $\left(77.3 \mathrm{ng} \mathrm{dl}^{-1}\right)$. Serum samples drawn from women at term, also showed no significant variation in levels of estradiol, estriol, or estrone between 50 white and 34 black mothers (Troisi et al, 2003a). As with the Henderson et al study, however, the authors reported that the black mothers had significantly higher testosterone levels than did white mothers. A similar lack of support for the oestrogen hypothesis was recently reported in a study comparing Chinese pregnant women to US white pregnant women. The Chinese women had significantly higher serum levels of estradiol and estriol at weeks 16 and 27 of gestation than did US white women (Hsieh et al, 2002). Chinese men, however, have a much lower incidence rate of TGCT than do US white men.

Our results are in agreement with these previously reported findings. We found significantly higher testosterone levels among black women in contrast with white women as did other studies: (Henderson et al, 1988; Troisi et al, 2003a). We also found higher total estradiol among black women than white women, which is in 
Table 2 Serum hormone concentrations between white and black mothers

\begin{tabular}{|c|c|c|c|c|c|c|}
\hline \multirow[b]{2}{*}{ Hormone } & \multicolumn{2}{|c|}{ White mothers $(n=150)$} & \multicolumn{2}{|c|}{ Black mothers $(n=150)$} & \multicolumn{2}{|c|}{ White vs black } \\
\hline & Mean $^{\mathrm{a}, \mathrm{b}}(95 \% \mathrm{Cl})$ & Mean $^{\mathrm{a}, \mathrm{c}}(95 \% \mathrm{Cl})$ & $\operatorname{Mean}^{\mathrm{a}, \mathrm{b}}(95 \% \mathrm{Cl})$ & Mean $^{a, c}(95 \% \mathrm{Cl})$ & $P^{\mathbf{b}}$ & $P^{c}$ \\
\hline \multicolumn{7}{|l|}{ First trimester ${ }^{d}$} \\
\hline Alphafetoprotein $\left(\mathrm{IU} \mathrm{ml^{-1 }}\right)$ & $6.9(6.1-7.8)$ & $7.0(6.1-8.1)$ & $10.7(9.5-12.2)$ & $10.5(9.1-12.0)$ & $<0.01$ & $<0.01$ \\
\hline Total estradiol $\left(\mathrm{ng} \mathrm{ml}^{-1}\right)$ & $2.3(2.1-2.6)$ & $2.2(2.0-2.5)$ & $2.5(2.3-2.8)$ & $2.6(2.4-2.9)$ & 0.26 & 0.05 \\
\hline Free estradiol $\left(\left.\mathrm{pg} \mathrm{ml}\right|^{-1}\right)$ & $24.6(22.7-26.6)$ & $23.5(21.5-25.7)$ & $24.8(22.9-26.8)$ & $25.9(23.7-28.3)$ & 0.89 & 0.17 \\
\hline $\begin{array}{l}\text { Free and albumin-bound } \\
\text { Estradiol }\left(\mathrm{pg} \mathrm{ml}^{-1}\right)\end{array}$ & $534.7(494.3-578.5)$ & $511.8(468.6-559.0)$ & $538.6(497.9-582.7)$ & $562.7(5|5.2-6| 4.6)$ & 0.90 & 0.18 \\
\hline Total estriol $\left(\mathrm{ng} \mathrm{ml}^{-1}\right)$ & $0.8(0.7-0.9)$ & $0.8(0.7-0.9)$ & $0.9(0.8-0.9)$ & $0.8(0.7-0.9)$ & 0.28 & 0.54 \\
\hline Total testosterone $\left(\mathrm{ng} \mathrm{ml}^{-1}\right)$ & $1.0(0.9-1.0)$ & $1.0(0.9-1.1)$ & $1.5(1.4-1.6)$ & $1.4(1.3-1.6)$ & $<0.01$ & $<0.01$ \\
\hline Free testosterone $\left(\mathrm{pg} \mathrm{ml}^{-1}\right)$ & $6.1(5.6-6.6)$ & $6.2(5.7-6.7)$ & $8.5(7.9-9.2)$ & $8.4(7.7-9.1)$ & $<0.01$ & $<0.01$ \\
\hline Free and albumin-bound testosterone ( $\mathrm{ng} \mathrm{dl}^{-1}$ ) & $12.8(11.8-13.8)$ & $13.0(12.0-14.2)$ & $17.9(16.6-19.3)$ & $17.5(16.1-19.1)$ & $<0.01$ & $<0.01$ \\
\hline Sex hormone binding globulin $\left(\mathrm{nmol} \mathrm{I}^{-1}\right)$ & $233.1(217.1-250.2)$ & $231.3(213.7-250.3)$ & $252.8(235.5-271.3)$ & $254.7(235.4-275.7)$ & 0.11 & 0.12 \\
\hline \multicolumn{7}{|l|}{ Ratios } \\
\hline Total estradiol/total testosterone & $2.4(2.2-2.6)$ & $2.2(2.0-2.5)$ & $1.7(1.6-1.9)$ & $1.8(1.6-2.0)$ & $<0.01$ & 0.01 \\
\hline Free estradiol/free testosterone & $4.1(3.7-4.5)$ & $3.8(3.4-4.2)$ & $2.9(2.6-3.2)$ & $3.1(2.8-3.5)$ & $<0.01$ & 0.02 \\
\hline Free and albumin-bound estradiol/free and albumin-bound testosterone & $41.9(38.0-46.3)$ & $39.3(35.2-43.9)$ & $30.1(27.2-33.2)$ & $32.1(28.7-35.8)$ & $<0.01$ & 0.02 \\
\hline \multicolumn{7}{|l|}{ Third trimester ${ }^{\mathrm{e}}$} \\
\hline Alphafetoprotein $\left(\mathrm{IU} \mathrm{ml}^{-1}\right)$ & | $89.5(\mid 75.3-204.9)$ & $180.3(165.6-196.3)$ & $207.9(192.3-224.8)$ & $218.5(200.7-237.8)$ & 0.10 & $<0.01$ \\
\hline Total estradiol $\left(\mathrm{ng} \mathrm{ml}^{-1}\right)$ & $19.2(17.9-20.5)$ & $19.2(17.8-20.7)$ & $18.5(17.3-19.7)$ & $18.4(17.1-19.9)$ & 0.44 & 0.51 \\
\hline Free estradiol $\left(\mathrm{pg} \mathrm{ml}^{-1}\right)^{\prime}$ & $119.5(1 \mid 1.5-128.1)$ & $117.2(108.3-126.7)$ & $106.3(99.1-113.9)$ & $108.4(100.2-117.3)$ & 0.02 & 0.21 \\
\hline Free and albumin-bound estradiol $\left(\mathrm{pg} \mathrm{ml}^{-1}\right)$ & $2599.1(2424.7-2786.0)$ & $2547.5(2355.3-2755.3)$ & $2309.6(2154.7-2475.7)$ & $2356.5(2178.7-2548.7)$ & 0.02 & 0.21 \\
\hline Total estriol $\left(\mathrm{ng} \mathrm{ml}^{-1}\right)$ & $11.2(10.1-11.9)$ & $11.7(11.0-12.6)$ & $11.3(10.6-12.0)$ & $10.8(10.1-11.6)$ & 0.83 & 0.13 \\
\hline Total testosterone $\left(\mathrm{ng} \mathrm{ml}^{-1}\right)$ & $1.2(1.1-1.3)$ & $1.3(1.2-1.4)$ & $2.0(1.8-2.1)$ & $1.9(1.7-2.0)$ & $<0.01$ & $<0.01$ \\
\hline Free testosterone $\left(\mathrm{pg} \mathrm{ml}^{-1}\right)$ & $1.3(1.2-1.3)$ & $1.3(1.2-1.4)$ & $1.7(1.6-1.7)$ & $1.6(1.5-1.7)$ & $<0.01$ & $<0.01$ \\
\hline Free and albumin-bound testosterone ( $\mathrm{ng} \mathrm{dl}^{-1}$ ) & $2.0(2.0-2.1)$ & $2.1(2.0-2.2)$ & $2.4(2.3-2.4)$ & $2.4(2.3-2.5)$ & $<0.01$ & $<0.01$ \\
\hline Sex hormone binding globulin $\left(\mathrm{nmol} \mathrm{I}^{-1}\right)$ & $503.2(478.3-529.5)$ & $5 \mid 4.4(486.3-544.2)$ & $544.7(517.7-573.1)$ & $532.9(503.7-563.7)$ & 0.03 & 0.43 \\
\hline \multicolumn{7}{|l|}{ Ratios } \\
\hline Total estradiol/total testosterone & $15.6(14.4-16.9)$ & $14.8(13.5-16.2)$ & $9.4(8.7-10.2)$ & $9.9(9.1-10.9)$ & $<0.01$ & $<0.01$ \\
\hline Free estradiol/free testosterone & $31.2(28.7-34.0)$ & $29.5(26.9-32.5)$ & $18.6(17.1-20.3)$ & $19.6(17.9-21.6)$ & $<0.01$ & $<0.01$ \\
\hline Free and albumin-bound estradiol/free and albumin-bound testosterone & $322.9(296.7-351.5)$ & $305.8(278.3-336.0)$ & $192.5(176.9-209.6)$ & $203.3(185.0-223.4)$ & $<0.01$ & $<0.01$ \\
\hline
\end{tabular}

${ }^{\mathrm{a} V a l u e s}$ are geometric means. ${ }^{\mathrm{b}}$ Adjusted for gestational age of blood draw (continuous). ${ }^{\mathrm{C}}$ Adjusted for maternal age at pregnancy (continuous), smoking at registration (ever/never), social economic index (continuous), gestational age of blood draw (continuous), and maternal weight (continuous). ${ }^{\mathrm{A}}$ Adjusted maternal weight was prepregnancy weight. ${ }^{\mathrm{e}}$ Adjusted maternal weight was weight at delivery. 
Table 3 Changes of hormone levels between first and third trimesters by racial groups and the significance of the changes between racial groups ${ }^{\mathrm{a}}$

\begin{tabular}{|c|c|c|c|c|c|}
\hline \multirow[b]{2}{*}{ Hormones } & \multicolumn{2}{|c|}{$\begin{array}{l}\text { White mothers } \\
\qquad(n=150)\end{array}$} & \multicolumn{2}{|c|}{$\begin{array}{l}\text { Black mothers } \\
\quad(n=150)\end{array}$} & \multirow{2}{*}{$\begin{array}{c}\text { White mothers vs } \\
\text { black mothers } \\
\text { P-value }\end{array}$} \\
\hline & Mean $^{b}$ & $P$-value & Mean $^{b}$ & $P$-value & \\
\hline Alphafetoprotein & 3.3 & $<0.01$ & 3.0 & $<0.01$ & $<0.01$ \\
\hline Total estradiol & 2.1 & $<0.01$ & 2.0 & $<0.01$ & 0.11 \\
\hline Free estradiol & 1.6 & $<0.01$ & 1.5 & $<0.01$ & 0.02 \\
\hline Free and albumin-bound estradiol & 1.6 & $<0.01$ & 1.5 & $<0.01$ & 0.02 \\
\hline Total estriol & 2.7 & $<0.01$ & 2.6 & $<0.01$ & 0.30 \\
\hline Total testosterone & 0.2 & $<0.01$ & 0.3 & $<0.01$ & 0.36 \\
\hline Free testosterone & -0.5 & $<0.01$ & -0.4 & $<0.01$ & 0.36 \\
\hline Free and albumin-bound testosterone & -0.5 & $<0.01$ & -0.4 & $<0.01$ & 0.36 \\
\hline Sex hormone binding globulin & 0.8 & $<0.01$ & 0.8 & $<0.01$ & 0.98 \\
\hline \multicolumn{6}{|l|}{ Ratios } \\
\hline Total estradiol/total testosterone & 1.9 & $<0.01$ & 1.7 & $<0.01$ & 0.01 \\
\hline Free estradiol/free testosterone & 2.1 & $<0.01$ & 1.9 & $<0.01$ & 0.01 \\
\hline Free and albumin-bound estradiol/free albumin-bound testosterone & 2.1 & $<0.01$ & 1.9 & $<0.01$ & 0.01 \\
\hline
\end{tabular}

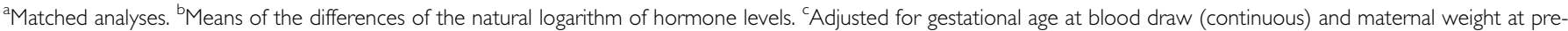
pregnancy and delivery (continuous).

Table 4 Correlations of hormone levels between first and third trimesters by racial groups

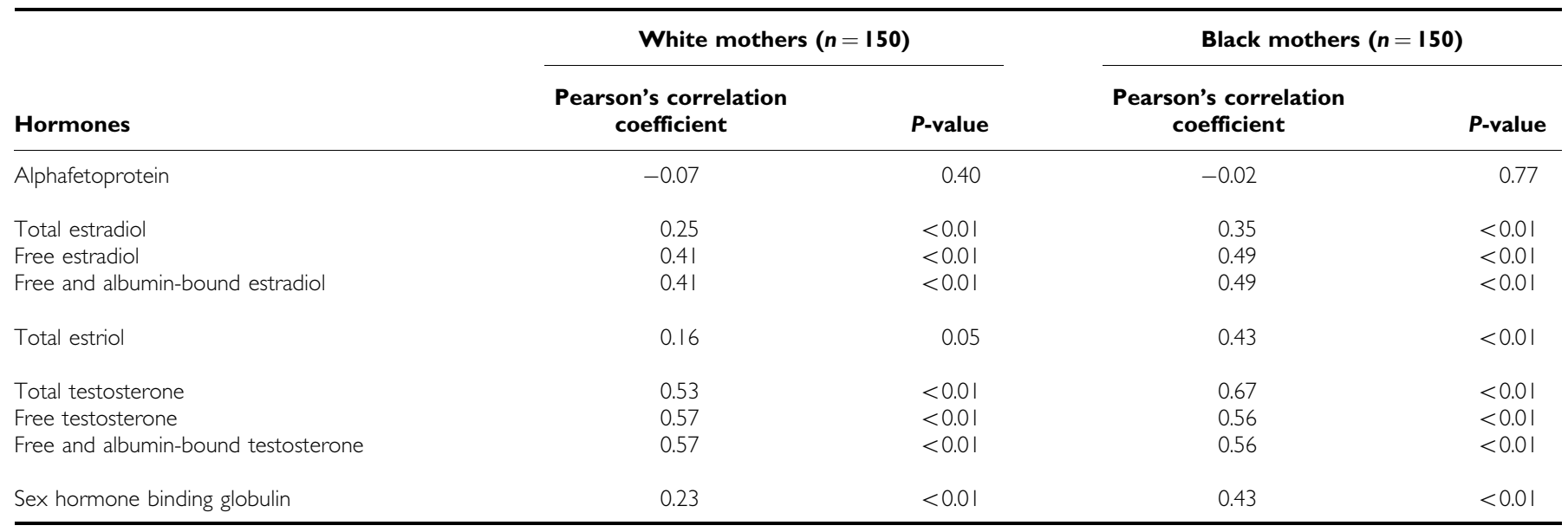

accord with other results (Henderson et al, 1988; Hsieh et al, 2002). If anything, these results may suggest that increased estradiol levels in first trimester are associated with reduced risk of TGCT, rather than increased risk. The $P$-value associated with the estradiol finding, however, just attained statistical significance and was unadjusted for multiple comparisons. An alternative explanation is that increased testosterone levels are associated with reduced risk of TGCT. Perhaps, however, it is not the absolute level of hormones that is critical, but the ratio of oestrogen to androgen. In the current study, black mothers had significantly lower ratios of sex hormones (oestrogens/androgens) than did white mothers during both the first and third trimesters. A lower ratio of total estradiol/total testosterone among black mothers has also been reported by others (Henderson et al, 1988).

Several studies have reported an association between maternal estriol and birthweight (Mucci et al, 2003). Parallel associations between increased birthweight and subsequent breast cancer risk have suggested that increased maternal estriol is a risk factor for breast cancer (Ahlgren et al, 2003). In contrast with breast cancer, most studies of birthweight and TGCT have reported that decreased birthweight, rather than increased birthweight, is a risk factor (Coupland et al, 2004), suggesting that maternal estriol levels might be lower in high-risk populations. The current study found some evidence to support this postulate. While there was no significant difference in estriol levels by ethnicity, black mothers did have higher estriol levels in third trimester than did white mothers as previously reported by Hsieh et al (2002), who found that second and third trimester estriol levels were significantly higher in Chinese mothers than in US white mothers.

A number of prior studies have examined ethnic differences in maternal serum AFP levels in second trimester. With some exceptions (Macri et al, 1976; Milunsky et al, 1980), the majority of studies have reported a higher level of weight-adjusted AFP among black mothers than white mothers (Crandall et al, 1983; Johnson, 1985; Baumgarten, 1986; Macri et al, 1987; Drugan et al, 1993; Benn et al, 1997; O'Brien et al, 1997). Ethnic differences in AFP levels during third trimester, however, have not been thoroughly studied. In the current research, weight-adjusted AFP 
levels were significantly higher among black mothers in both first and third trimesters. There was not, however, a significant correlation in either black or white mothers between first and third trimester levels of AFP. This lack of correlation may indicate that events during pregnancy influence AFP level more than they do levels of oestrogens and androgens, as the vast majority of AFP is produced by the fetus.

The current study has some strengths as well as some weaknesses. A major strength was the relatively large sample size, which granted sufficient statistical power to test the study hypothesis in both first and third trimesters. Another strength is that mothers of babies with conditions associated with aberrant hormone levels were excluded from the study. In addition, matching on the closest gestational age at blood draw for both first and third trimester decreased the likelihood of confounding by gestational age. A potential weakness of the study was the fact that the hormone levels were measured on samples that had been stored for roughly 40 years. Although long-term storage might have affected the hormone levels somewhat, it is unlikely that the bias is great as the levels in the current study are equivalent to levels reported in other studies examining newly drawn samples (Lipworth et al, 1999). A final weakness of the study is that it examined maternal hormone levels rather than fetal hormone levels and may not have been an accurate approximation of the in utero hormonal milieu. Comparisons of maternal and umbilical cord hormone levels found little correlation between the levels at term (Troisi et al, 2003b). Whether there is any correlation between maternal and fetal levels is not presently known and is unlikely to be examined until hormone assays on very small amounts of blood can be perfected. Given the uncertainty of the maternal-fetal correlations at the present time, the results of this, and other studies based on maternal levels, should be accepted with some caution.

In conclusion, the current study found little evidence to support the hypothesis that increased maternal oestrogen levels are associated with increased risk of TGCT. The data are consistent with several other hypotheses, however. Increased estradiol in first trimester may be associated with decreased risk of TGCT. Increased testosterone and/or increased AFP throughout pregnancy may be associated with decreased risk of TGCT, although a relationship with AFP seems somewhat unlikely. Decreased ratios of oestrogens/androgens throughout pregnancy may be associated with decreased risk of TGCT. Finally, an increased risk of estriol in third trimester may be associated with decreased risk of TGCT.

\section{REFERENCES}

Ahlgren M, Sorensen T, Wohlfahrt J, Haflidadottir A, Holst C, Melbye M (2003) Birth weight and risk of breast cancer in a cohort of 106,504 women. Int J Cancer 107: $997-1000$

Baumgarten A (1986) Racial difference and biological significance of maternal serum alpha-fetoprotein. Lancet 2: 573

Benn PA, Clive JM, Collins R (1997) Medians for second-trimester maternal serum alpha-fetoprotein, human chorionic gonadotropin, and unconjugated estriol; differences between races or ethnic groups. Clin Chem 43: $333-337$

Coupland CA, Forman D, Chilvers CE, Davey G, Pike MC, Oliver RT (2004) Maternal risk factors for testicular cancer: a population-based casecontrol study (UK). Cancer Causes Control 15: 277-283

Crandall BF, Lebherz TB, Schroth PC, Matsumoto M (1983) Alphafetoprotein concentrations in maternal serum: relation to race and body weight. Clin Chem 29: $531-533$

Drugan A, O’Brien JE, Gambino R, Johnson MP, Evans MI (1993) Similarity of twins to singleton maternal serum alpha-fetoprotein ratio by race: no need to establish specific multifetal tables. Fetal Diagn Ther 8: 84-88

Emmen JM, McLuskey A, Adham IM, Engel W, Verhoef-Post M, Themmen AP, Grootegoed JA, Brinkmann AO (2000) Involvement of insulin-like factor 3 (Insl3) in diethylstilbestrol-induced cryptorchidism. Endocrino$\log y$ 141: 846-849

Goebelsman U, Bernstein GS, Gale JA, Kletzky OA, Nakamura RM, Coulson AH, Korelitz JJ (1979) Serum gonadotropin, testosterone, estradiol and estrone levels prior to and following bilateral vasectomy. In Vasectomy: Immunologic and Pathophysiologic Effects in Animals and Man, Lepow IH, Crozer R (eds) pp 165-175. New York: Academic Press

Henderson BE, Benton B, Jing J, Yu MC, Pike MC (1979) Risk factors for cancer of the testis in young men. Int J Cancer 23: 598-602

Henderson BE, Bernstein L, Ross RK, Depue RH, Judd HL (1988) The early in utero oestrogen and testosterone environment of blacks and whites: potential effects on male offspring. Br J Cancer 57: 216-218

Hsieh CC, Lambe M, Trichopoulos D, Ekbom A, Akre O, Adami HO (2002) Early life exposure to oestrogen and testicular cancer risk: evidence against an aetiological hypothesis. Br J Cancer 86: 1363 - 1364

Johnson AM (1985) Racial differences in maternal serum alpha-fetoprotein screening. In Alpha-Fetoprotein and Congenital Disorders, Mizejewski GJ, Poter IH (eds) pp 183-196. New York: Academic Press

Katagiri H, Stanczyk FZ, Goebelsmann U (1974) Estriol in pregnancy. III. Development, comparison and use of specific antisera for rapid radioimmunoassay of unconjugated estriol in pregnancy plasma. Steroids 24: $225-238$

Lipworth L, Hsieh CC, Wide L, Ekbom A, Yu SZ, Yu GP, Xu B, Hellerstein S, Carlstrom K, Trichopoulos D, Adami HO (1999) Maternal pregnancy hormone levels in an area with a high incidence (Boston, USA) and in an area with a low incidence (Shanghai, China) of breast cancer. Br J Cancer 79: $7-12$

Macri JN, Kasturi RV, Hu MG, Krantz DA, Douros TJ, Sajda P, Cook EJ (1987) Maternal serum alpha-fetoprotein screening. III. Pitfalls in evaluating black gravid women. Am J Obstet Gynecol 157: 820-822

Macri JN, Weiss RR, Elligers KW, Federgreen WR (1976) Letter: Racial differences in maternal serum-alpha-fetoprotein. Lancet 1: 207-208

McGlynn KA, Devesa SS, Sigurdson AJ, Brown LM, Tsao L, Tarone RE (2003) Trends in the incidence of testicular germ cell tumors in the United States. Cancer 97: 63-70

Milunsky A, Alpert E, Neff RK, Frigoletto Jr FD (1980) Prenatal diagnosis of neural tube defects. IV. Maternal serum alpha-fetoprotein screening. Obstet Gynecol 55: 60-66

Moller H, Skakkebaek NE (1997) Testicular cancer and cryptorchidism in relation to prenatal factors: case-control studies in Denmark. Cancer Causes Control 8: 904-912

Mucci LA, Lagiou P, Tamimi RM, Hsieh CC, Adami HO, Trichopoulos D (2003) Pregnancy estriol, estradiol, progesterone and prolactin in relation to birth weight and other birth size variables (United States). Cancer Causes Control 14: $311-318$

Nef S, Parada LF (1999) Cryptorchidism in mice mutant for Insl3. Nat Genet 22: 295-299

Nef S, Shipman T, Parada LF (2000) A molecular basis for estrogen-induced cryptorchidism. Dev Biol 224: 354-361

Niswander KR, Gordon M (1972) The women and their pregnancies. US Department of Health, Education, and Welfare

O’Brien JE, Dvorin E, Drugan A, Johnson MP, Yaron Y, Evans MI (1997) Race-ethnicity-specific variation in multiple-marker biochemical screening: alpha-fetoprotein, hCG, and estriol. Obstet Gynecol 89: $355-358$

Rajpert-De Meyts E, Jorgensen N, Brondum-Nielsen K, Muller J, Skakkebaek NE (1998) Developmental arrest of germ cells in the pathogenesis of germ cell neoplasia. Apmis 106: 198-204; discussion 204-206

Ries LAG, Eisner MP, Kosary CL, Hankey BF, Miller BA, Clegg L, Mariotto A, Fay MP, Feuer EJ, Edwards BK (eds). (2004) SEER Cancer Statistics Review, 1975-2000. Bethesda, MD: National Cancer Institute http:// seer.cancer.gov/csr/1975_2000/, 2003

Rorth M, Rajpert-De Meyts E, Andersson L, Dieckmann KP, Fossa SD, Grigor KM, Hendry WF, Herr HW, Looijenga LH, Oosterhuis JW, Skakkebaek NE (2000) Carcinoma in situ in the testis. Scand J Urol Nephrol Suppl 205: 166-186

Sabroe S, Olsen J (1998) Perinatal correlates of specific histological types of testicular cancer in patients below 35 years of age: a case-cohort study based on midwives' records in Denmark. Int J Cancer 78: 140-143 
Sharpe RM (2003) The 'oestrogen hypothesis' - where do we stand now? Int J Androl 26: $2-15$

Sharpe RM, Skakkebaek NE (1993) Are oestrogens involved in falling sperm counts and disorders of the male reproductive tract? Lancet 341: $1392-1395$

Skakkebaek NE, Rajpert-De Meyts E, Main KM (2001) Testicular dysgenesis syndrome: an increasingly common developmental disorder with environmental aspects. Hum Reprod 16: $972-978$

Sodergard R, Backstrom T, Shanbhag V, Carstensen H (1982) Calculation of free and bound fractions of testosterone and estradiol-17 beta to human plasma proteins at body temperature. J Steroid Biochem 16: $801-810$
Troisi R, Potischman N, Roberts J, Siiteri P, Daftary A, Sims C, Hoover RN (2003a) Associations of maternal and umbilical cord hormone concentrations with maternal, gestational and neonatal factors (United States). Cancer Causes Control 14: $347-355$

Troisi R, Potischman N, Roberts JM, Harger G, Markovic N, Cole B, Lykins D, Siiteri P, Hoover RN (2003b) Correlation of serum hormone concentrations in maternal and umbilical cord samples. Cancer Epidemiol Biomarkers Prev 12: $452-456$

Zheng T, Holford TR, Ma Z, Ward BA, Flannery J, Boyle P (1996) Continuing increase in incidence of germ-cell testis cancer in young adults: experience from Connecticut, USA, 1935-1992. Int J Cancer 65: $723-729$ 